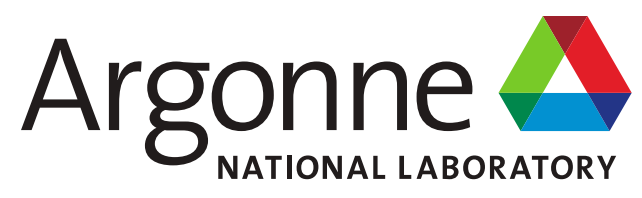

\title{
Thermal Conductivity Measurement of Microstructure in Irradiated Materials
}

Chemical and Fuel Cycle Technologies Division 


\title{
About Argonne National Laboratory
}

Argonne is a U.S. Department of Energy laboratory managed by UChicago Argonne, LLC under contract DE-AC02-06CH11357. The Laboratory's main facility is outside Chicago, at 9700 South Cass Avenue, Lemont, Illinois 60439. For information about Argonne and its pioneering science and technology programs, see www.anl.gov.

\section{DOCUMENT AVAILABILITY}

Online Access: U.S. Department of Energy (DOE) reports produced after 1991 and a growing number of pre-1991 documents are available free at OSTI.GOV (http://www.osti.gov/), a service of the U.S. Dept. of Energy's Office of Scientific and Technical Information.

\author{
Reports not in digital format may be purchased by the public from the \\ National Technical Information Service (NTIS): \\ U.S. Department of Commerce \\ National Technical Information Service \\ 5301 Shawnee Rd \\ Alexandria, VA 22312 \\ www.ntis.gov \\ Phone: (800) 553-NTIS (6847) or (703) \\ 605-6000 Fax: (703) 605-6900 \\ Email: orders@ntis.gov
}

\section{Reports not in digital format are available to DOE and DOE contractors from the Office of Scientific and Technical Information (OSTI):}

U.S. Department of Energy

Office of Scientific and Technical Information

P.O. Box 62

Oak Ridge, TN 37831-0062

www.osti.gov

Phone: (865) 576-8401

Fax: (865) 576-5728

Email: reports@osti.gov

Disclaimer

\section{Disclaimer}

This report was prepared as an account of work sponsored by an agency of the United States Government. Neither the United States Government nor any agency thereof, nor UChicago Argonne, LLC, nor any of their employees or officers, makes any warranty, express or implied, or assumes any legal liability or responsibility for the accuracy, completeness, or usefulness of any information, apparatus, product, or process disclosed, or represents that its use would not infringe privately owned rights. Reference herein to any specific commercial product, process, or service by trade name, trademark, manufacturer, or otherwise, does not necessarily constitute or imply its endorsement, recommendation, or favoring by the United States Government or any agency thereof. The views and opinions of document authors expressed herein do not necessarily state or reflect those of the United States Government or any agency thereof, Argonne National Laboratory, or UChicago Argonne, LLC. 


\section{Thermal Conductivity Measurement of Microstructure in Irradiated Materials}

prepared by

Yinbin Miao ${ }^{1}$, Sanjiv Sinha ${ }^{2}$, and Abdellatif Yacout $^{1}$

1) Chemical and Fuel Cycle Technologies Division, Argonne National Laboratory

2) University of Illinois Urbana-Champaign

June 2021 
(This page left intentionally blank) 


\section{Abstract}

Argonne National Laboratory is establishing additional capabilities for advanced techniques for accelerated experiment-based fuel material screening. A key supporting element is expanded capabilities for the characterization of irradiated samples, including establishment of the capability to measure irradiated fuel thermal conductivity at the micro-scale level. Argonne is collaborating with the University of Illinois at Urbana-Champaign (UIUC) to adopt the suspended bridge method to measure thermal conductivity of radiation-induced microstructures in nuclear materials directly. The initial phase of work to support thermal conductivity measurements of microstructure in irradiated materials at Argonne has been executed, and is summarized here. This report is intended to serve as a status update for this activity, summarizing work completed in FY20. 


\section{Table of Contents}

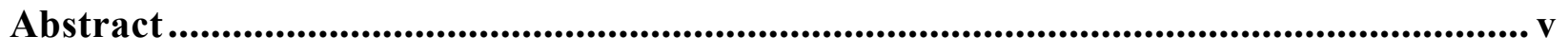

Table of Contents .............................................................................................. vi

1 Introduction ............................................................................................. 7

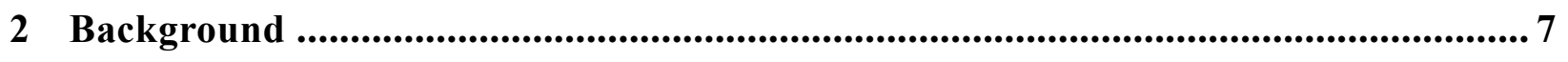

3 Capability Establishment at Argonne .................................................................... 9

4 High-Temperature Capability Development at UIUC ............................................ 11

5 Status Summary and Future Work ..................................................................... 13

Acknowledgement ......................................................................................... 13 


\section{Introduction}

Argonne National Laboratory is establishing additional capabilities for advanced techniques for accelerated experiment-based fuel material screening. The major work in this area is the upgrade of the Argonne Tandem Linac Accelerator System (ATLAS), for expanded opportunities for ion irradiation testing of nuclear fuels and other materials. As part of the broader activity associated with the ATLAS Upgrade, Argonne is also establishing expanded capabilities for the characterization of irradiated samples, including (1) procurement and installation of a transmission electron microscope, and (2) establishment of the capability to measure irradiated fuel thermal conductivity at the micro-scale level. This capability will be particularly beneficial for evaluating samples from ion irradiation, which have a damage zone of a few microns.

The initial phase of work to support thermal conductivity measurements of microstructure in irradiated materials has been executed. FY20 accomplishments and remaining FY21 tasks for the establishment of this capability at ANL are described here.

\section{Background}

Under harsh environments in nuclear reactors, microstructure in materials evolves and thereby alters macroscopic properties and performance. To be specific, thermal conductivity of nuclear materials usually suffers degradation during irradiation due to the formation of cavities, precipitates, interaction layers, etc. To predict the performance of nuclear materials with high fidelity, their thermal conductivity degradation originating from microstructural modifications must be well understood. However, conventional thermal conductivity measurement methods designed for bulk specimens with nearly homogeneous structure, such as laser flash, cannot be used to measure the contributions of these lower-length-scale (LLS) structures induced by irradiation to thermal conductivity degradation.

In the current work, Argonne has been collaborating with University of Illinois at UrbanaChampaign (UIUC) to adopt the suspended bridge method to measure thermal conductivity of 
radiation-induced microstructures in nuclear materials directly. Suspended bridge method is a microfabrication-based technology that was originally developed to measure thermal conductivity of 1D or nearly 1D nano-materials such as carbon nanotubes and silicon nanowire. Hence, the technology is intrinsically suitable for thermal conductivity measurement of LLS structures induced by irradiation. Under the aforementioned collaboration, the combination of focused ion beam (FIB) based sample preparation and suspended bridge method has proven to be capable of measuring thermal conductivity accurately for those radiation-induced LLS structures that cannot be handled by the conventional approach.

The key aLEU Fuel project activities on thermal conductivity measurement are twofold: (1) establishment of suspended bridge method capability at Argonne; and (2) development of advanced suspended bridge method that can be used up to $1000 \mathrm{~K}$. 


\section{Capability Establishment at Argonne}

The suspended bridge method for nuclear material applications includes the following steps:

(1) Sample irradiation (ion or in-pile);

(2) Measurement platform chip microfabrication;

(3) Nanorod specimen preparation and mounting (FIB);

(4) Chip packaging (wire bonded to chip carrier);

(5) Measurement;

(6) Data analysis.

During the proof of concept stage, steps (1), (3), and (6) were performed at Argonne, while Steps (2), (4), and (5) were conducted at UIUC because the university has established infrastructure. However, due to both safety and security concerns, the chip packaging and measurement stages of this process would be better performed at Argonne so that no nuclear materials will need to be transferred to the university. Therefore, the FY20 activities at Argonne were focused on establishing capabilities of Steps (4) and (5) locally. Chip packaging is a standard procedure done by a commercially available device, a wire bonder. In FY20, a MPP iBond500 wire bonder was purchased. Due to the pandemic, the installation and training was delayed, which is expected to complete in early FY21.

The major achievement at Argonne is the establishment of the suspended bridge measurement device with technical support from UIUC (Figure 1). This device was designed based on the existing setup at UIUC with appropriate upgrade so that it can be upgraded to have hightemperature capability in the future. The device consists of a cryostat-based sample chamber, a computer controller, and a series of precise instruments including two Keithley 6221 AC/DC current sources and four SR830 lock-in amplifiers. All the instruments are connected together to the computer controller using IEEE 488 (GPIB) cables. A LabVIEW Virtual Instrument (VI) was developed based on UIUC's VI with appropriate modifications for the upgraded instruments, firmware and software. 


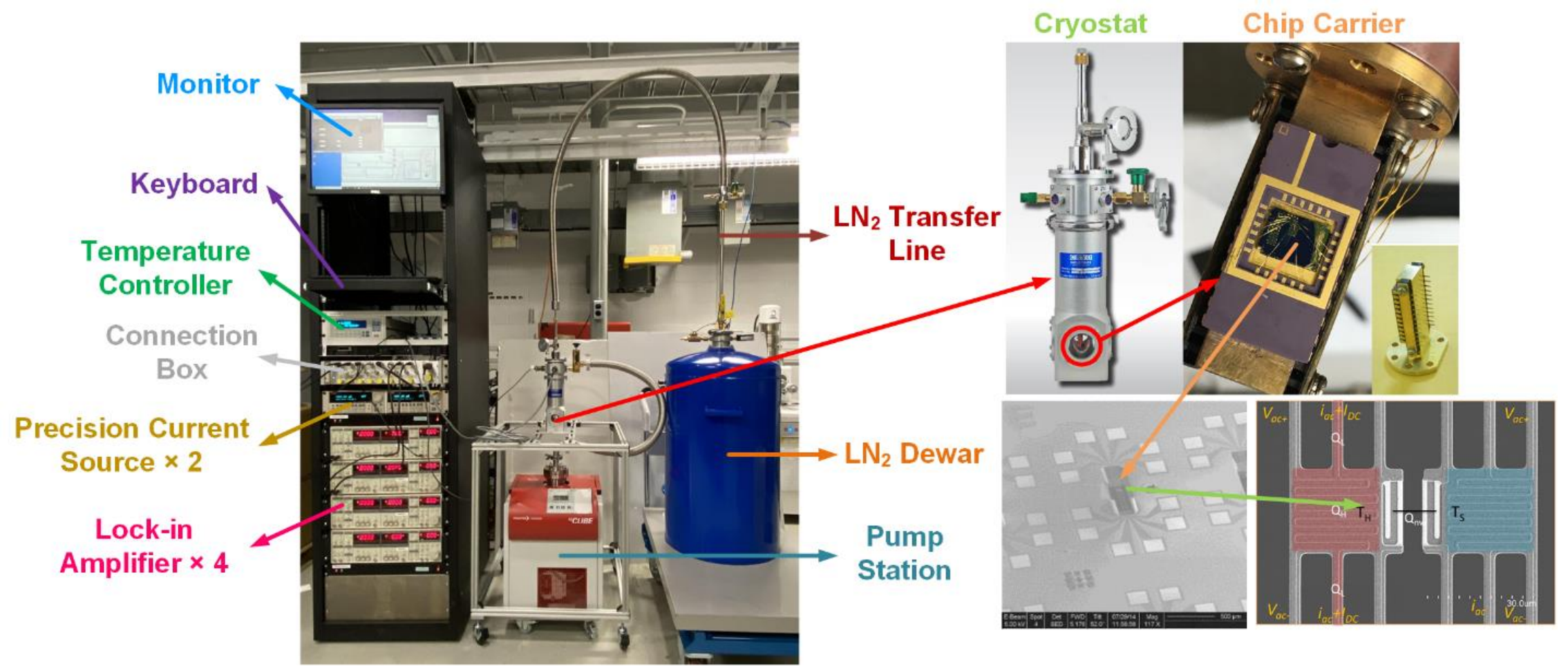

Figure 1. Suspended bridge measurement device established at Argonne 


\section{High-Temperature Capability Development at UIUC}

Previous ANL-UIUC thermal conductivity collaboration work was focused on thermal conductivity measurements of nanowire samples in the temperature range of $300 \mathrm{~K}-360 \mathrm{~K}$. Starting from FY20, the UIUC group have been working towards expanding the experimental capabilities to conduct thermal conductivity measurements at very high temperatures up to (and even beyond) $1000 \mathrm{~K}$.

The temperature measurements are highly affected by heat loss due to radiation at such high temperatures. A promising way to control radiation heat loss is to add an additional radiation shielding around the sample holder as shown in Figure 2.

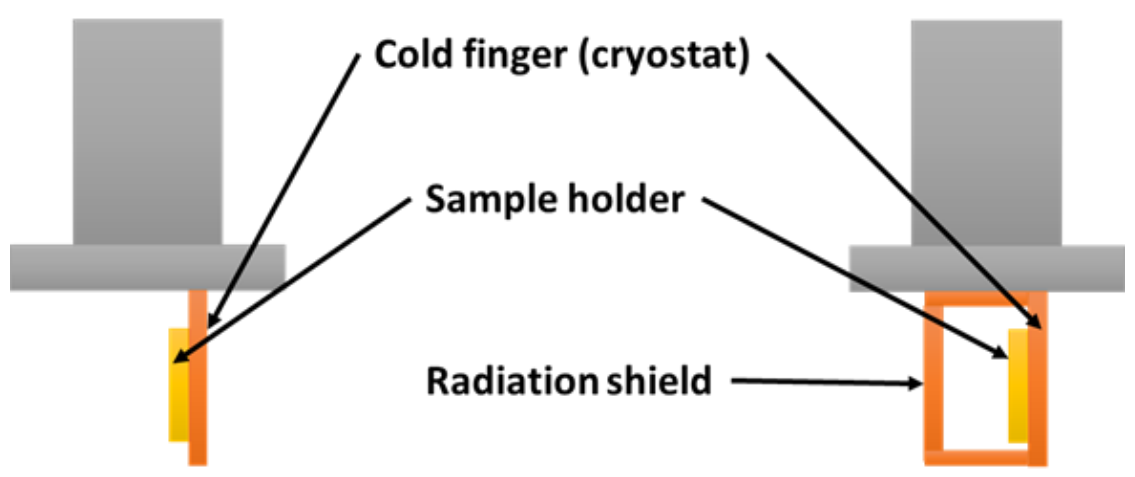

(a)

(b)

Figure 2. (a) Cryostat cold finger made of copper with the ceramic sample holder attached. (b) Cryostat cold finger with a radiation shield above the ceramic sample holder.

The purpose of the radiation shield is to reflect the emitted radiation from the sample back on to the sample. Hence, the material of the radiation shield should possess high spectral reflectivity and low emissivity in the temperature range of interest. Copper was selected as the material for the radiation due its low emissivity, $\varepsilon=0.07$ and high reflectivity, $\rho \approx 1$. Computational simulations were performed in COMSOL Multiphysics to quantify the effect of radiation shield. Fig. 3(a) shows the temperature distribution of the sample holder and cold finger with and without the radiation shield when the temperature of the bottom surface of cold finger is set at $1500 \mathrm{~K}$. The radiation shield helps in keeping the sample holder temperature close to the cold finger temperature. Fig. 3(b) shows the difference in sample holder temperature with and without the 
radiation shield for different cold finger temperatures. The effect of radiation shield becomes more prominent at very high cold finger temperatures.

Moving forward it is planned to refine the computational model with respect to dimensions and material properties of the radiation shield. The technical team will explore the idea of using refractory coatings to ensure better shielding. The near-term goal will be to finalize the experimental setup modifications to incorporate high temperature measurements.

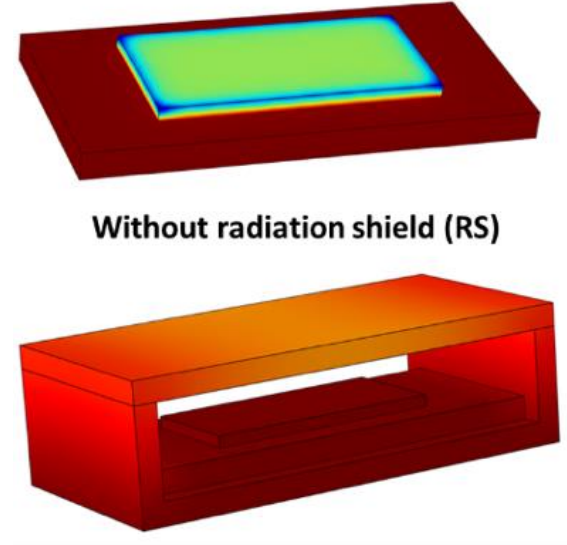

With radiation shield (RS)

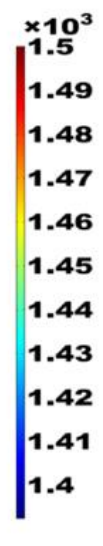

(a)

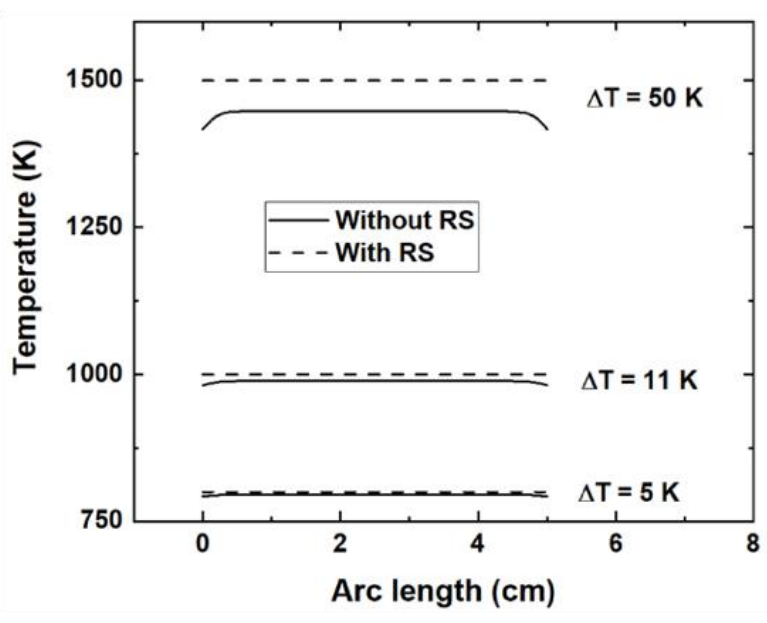

(b)

Figure 3. (a) Temperature distribution of the sample holder and cold finger geometry in the presence and absence of radiation shield. (b) Temperature variation along the centerline of the sample holder at cold finger temperatures of $800 \mathrm{~K}, 1000 \mathrm{~K}$ and $1500 \mathrm{~K}$. 


\section{Status Summary and Future Work}

Due to the COVID-19 pandemic, the experimental activities at UIUC were affected in FY20. Therefore, the FY20 work at the university was focused on design. A no-cost subcontract extension was made so that UIUC can continue the development in FY21.

A summary of the accomplishments in FY20 is as follows:

- Components of the system were procured at ANL.

- Components were assembled at ANL, with initial testing of the equipment using resistor boxes to mimic real samples.

- UIUC began work on the design of the high temperature capability.

The key steps of the remaining work in FY21 are:

- Continued testing of the equipment at ANL, using real chip-mounted miniature samples in cryostat.

- Install the wire bonder, and complete equipment setup.

- Final design and assembly of the high-temperature capability at UIUC, and transfer of this capability to ANL.

In addition, in FY21 it is planned to begin using the equipment for initial radiological samples. The establishment of this capability for measurement of irradiated fuel thermal conductivity at the micro-scale level will provide significant benefits in advancing ANL's ability to characterize the properties of irradiated nuclear fuel materials.

\section{Acknowledgement}

This work was sponsored by the U.S. Department of Energy, Office of Nonproliferation Research and Development in the U.S. National Nuclear Security Administration Office of Defense Nuclear Nonproliferation under Contract DE-AC02-06CH11357. 


\section{Argonne $\mathbf{A}$}

\section{Nuclear Science \& Engineering Division}

Argonne National Laboratory

9700 South Cass Avenue, Bldg. 208

Argonne, IL 60439

www.anl.gov 